\title{
CERTAIN FAITH: WHAT KIND OF CERTAINTY?1
}

\author{
Lesslie Newbigin
}

\section{Summary}

A frequent cause of mutual alienation among Christians is the charge of too much certainty on the one hand and too little certainty on the other. How do we find a kind of certainty which is confident and yet humble and teachable? We are heirs of an Enlightenment which took as the ideal of knowledge an 'objectivity' which pretended to eliminate all the subjective factors in human knowing and to provide indubitable certainty. This has led into the collapse, of belief in objective truth, scepticism and nihilism. Christian affirmation of the truth of the Gospel must not fall victim to a false concept of objectivity but must take the form of personal commitment to a faithful God.

Recently I have heard on several occasions Christians accusing one another, either of too much certainty, or of too little. We are all familiar with both accusations. There is, on the one hand, the charge against 'fundamentalist' Christians that they are arrogant, bigoted and blind to issues which might call their certainties into question. There is also the counter-charge nicely encapsulated in a collect by the late Ronald Knox:

O Lord, for as much as without Thee

We are not able to doubt Thee,

Grant us the grace

To tell the whole race

We know nothing whatever about Thee.

Is there a stable position between these two extremes where a Christian can stand with confidence?

It is worth noting at the outset that this kind of debate goes on only in a limited part of our intellectual world. One does not hear the same kind of slanging match going on among scientists. They are in the habit of making confident statements about what is the case without, apparently, being troubled by the charge of arrogance. To put the matter in another way, there is a large area of our public life where pluralism does not

1This paper is based on a lecture delivered to the Tyndale Fellowship Ethics Study Group in July 1993. 
reign. When two scientists, one in Chicago and the other in Tokyo, conduct the same experiment but come up with radically different results, they do not take it as an opportunity for celebrating the joy of living in a pluralist society. They do not put the difference down to differences in culture or the psychology of the two scientists. They argue the matter until they find a resolution to the difference, either by showing that one is wrong, or that both are only partially right. Our shared intellectual world thus has a rift down the middle: on one side one can use the language of assured certainty without incurring the charge of bigotry; on the other side one cannot. A Ph.D. student in this university recently wrote to me with the following problem: he had submitted the outline for his proposed dissertation. It had been accepted by his supervisor except for one chapter which he was told to remove, since it dealt with matters of faith, not of fact, and was therefore inadmissible. Faith is one thing, facts are something else. Let us examine this dichotomy.

I suppose that the operative definition of faith in the Anglo-Saxon world is the one offered by John Locke: it is 'a persuasion which falls short of knowledge'. To say 'I believe' is to say something decidedly weaker than 'I know'. Compare this with the famous slogan of St Augustine: Credo ut intelligam. I believe in order to know. Faith is not a substitute for knowledge but the only way to knowledge.

If we reflect on ordinary human experience we will surely see that this is the right way of stating the relation between faith and knowledge. The first step in learning to know anything is the opening of the mind to accept in faith what is given-the evidence of our senses, the way our parents use words to designate things and express meanings. The child beginning at school has to accept in faith the words of the teacher. The university student embarking on a new field of study has to begin by believing the authorised text books. Of course, in all these cases, one may have to question what one first accepted in faith, but one can only do so on the basis of other knowledge which one has acquired by the same route. One cannot learn anything except by believing something.

This way of relating faith to knowledge was, I suppose, operative during the thousand years in which the Bible wasliterally-the book, the one basis, accepted in faith, for the 
whole intellectual activity of European society. But a profound change took place in the 11th and 12th centuries when the great Muslim commentaries on Aristotle were translated into Latin and western Christendom had to meet the powerful challenge of Aristotelian rationalism. It was this challenge which created the immense intellectual ferment that marked the ending of the middle ages and produced (among other results) the foundation of the great universities of Bologna, Paris, Oxford and Cambridge. (The tassel that adorns the academic hood to this day is the tassel taken from the Muslim fez). From the same source came the replacement of the old Roman system of enumeration by the Arabic numerals, which opened the way for the development of that which was to be the lingua franca of the new Europe-mathematics.

How was Christendom to respond to this challenge? The first response was resistance. The teaching of Aristotle was banned by the Pope. But this could not be the final answer. The challenge of 'The Philosopher' had to be met. To do so was the great work of St Thomas Aquinas who developed a synthesis of Aristotelian rationalism with the biblical tradition which has shaped the thought of western Christendom to this day. But the synthesis was achieved at the cost of a dichotomy which had far-reaching implications. There were two ways to knowledge. There were things which could be known by the power of reason alone, including the existence of God. There were other things which could only be known by divine revelation received in faith-such as the Incarnation, the Atonement and the Trinity. What Augustine had seen as one was now split in two. The enterprise of human knowing is no longer a single enterprise; it is two different enterprises working with two different methods. Two problems relevant to our discussion have resulted from this move. The first is that there is clearly a difference between the God whose existence is demonstrated by the use of Aristotelian logic and the God who encounters us in the Bible. The problem is: which is the true God? Is the God of the philosophers, the God of natural theology, the true God? If so, are we to understand the God of the Bible as an anthropomorphic distortion due to the immaturity of the human mind? Or, contrariwise, is the God of the Bible the true God? If so, must we not see the God of the philosophers as a construction of the human mind, perhaps an image in the clouds like 
Feuerbach's Brockenspectre, in fact an idol? That dilemma, so vividly expressed by Pascal in his famous fragment, is with us still.

The other problem arises from the fragility of the proofs for the existence of God. If the biblical revelation is not enough to sustain belief, if we require something more reliable than what is given in the Gospel, if we have to rely on the philosopher to give us certainty, then the philosophic reasoning must be impeccable. The proofs must be watertight. But they are not. The centuries following Aquinas saw the shadow of scepticism spreading across the mind of Christendom. When we reach the 16 th and 17th centuries it has become almost overwhelming. Uncertainty was accentuated by the discoveries of the new science which upset what seemed to be indubitable certainties-such as that the sun rises in the east and sets in the west, and that the earth is stable under our feet. According to Michael Buckley the question debated all over France in the early years of the 17th century was 'Is there any escape from scepticism?'2

It was a young philosopher in Paris who claimed to have an answer to this question, and who was given a commission by a cardinal of the Church to employ his philosophical methods to provide certain proofs of the existence of God. René Descartes undertook this commission, though his method was designed for a much wider use. Descartes' method can be described as involving three steps:

(1) Begin with something which is self evident and indubitable. In the sceptical climate of his time, Descartes began with what was common to him and to the sceptics: scepticism involves thinking. Inasmuch as I doubt, I think. If I think, I am. Here is an indubitable starting point.

(2) From this Descartes proceeded by deductive reasoning having the clarity, precision, and indubitability of mathematics. By such rational means he would construct a world of indubitable facts.

(3) All claims to knowledge are to be tested by the criteria here provided. What fails the test of certainty is not knowledge, but only belief. The critical principle is the key to certain

${ }^{2}$ M. Buckley, At the Origins of Modern Atheism (New Haven, Yale University Press 1987). 
knowledge. The way to certainty is to question every claim to knowledge and accept only what can be shown to be indubitably certain. Descartes has thus precisely reversed Augustine. The way to certain knowledge is not faith but doubt.

If one stands back for a moment and looks at Descartes' method from the standpoint of another world-view-that of the Bible, for example, or that of Indian thought-it is obvious that Descartes is laying down the terms on which he will accept the evidence which reality offers of itself to the human mind. One may remark, for example, that it is not self-evident that fallible human beings should be capable of infallible knowledge. And indeed, as we know, Descartes' method has been found to have in itself the seeds of its own destruction. For the critical principle turns upon itself and eventually destroys itself. The reason is simple, namely that we can only (if we are rational) criticise a proposition on the ground of other propositions which we hold to be true. But these propositions are themselves open to the critical knife. The intellectual life of Europe since Descartes has remained under the shadow of scepticism, perhaps most pervasively present in the affirmation of Kant that we cannot know the realities with which we have to deal, but only their appearances. This has become so much an axiom of 'modern' thought that any claim to speak of ultimate realities (of God) is automatically discounted as merely private opinion. The self-contradictory character of this supposed axiom is hardly noticed, yet it obviously implies a claim to know something about ultimate reality, namely that it is unknowable. One has to ask for the evidence for this claim.

The inevitable conclusion was that drawn by F.W. Nietzsche and the 'post modernists' who are his disciples. All claims to know truth must be recognised as assertions of the will to power. Human history is the record of successive 'regimes of truth' (Michel Foucault) which, one after another, displace their predecessors and impose their own 'truth' upon society, but there is no 'meta-narrative' which provides an over-arching truth by which they might all be judged. The end is the nihilism into which our society is visibly sinking around us. Ironically, the demand for certainty has led directly into total scepticism. 
The method of Descartes, and particularly the choice he made for his starting point-the self as thinking, rather than the self as acting or the self as loving-had the effect of reopening dualisms which classical thought had not been able to overcome but from which biblical thought was freed. One can distinguish three distinct though related dualisms.

\section{(1) Mind and Matter}

Descartes pictured the human mind not as part of a total human being, and therefore part of the natural world of which human life is a part, but as an entity which-so to speak-looks in at the cosmos from outside. The mental, or spiritual, and the material are two different realities which have (apparently) no way of being connected in one whole. Obviously the human brain is part of the natural world which can be investigated by the methods of natural science. But what is the human mind-if indeed it exists at all? Here the dualism of classical thought reappears and has become so much a part of unexamined assumptions that we take for granted that 'material concerns' and 'spiritual concerns' are two separate and antithetical concerns.

\section{(2) Subjective and Objective}

All human knowing is the activity of a human subject, but it seeks contact with objects which are beyond the human mind. This seeking of contact with a reality beyond the thinking self is what we mean by seeking to know. But in the picture which Descartes has bequeathed to us, we are given the illusion of a kind of knowledge which is 'objective' in the sense that it is cleansed of all 'subjective' (and therefore fallible) elements. For long periods, especially in the 19th century, popularisers of science as an alternative to religion propagated the idea that 'scientific' knowledge was 'objective' in this sense, and that other claims to knowledge such as the claim to recognise beauty or goodness were subjective. They did not give information about a reality beyond the human mind, but only about that mind itself.

\section{(3) Theory and Practice}

These words, which come from the Greek and are absent from the Bible, represent another form of the dualism which 
Descartes has bequeathed to us. Since the human mind belongs (if it exists) to a realm of being quite separate from the material world in which action takes place, there is a gap between the process by which one envisages how things are or what ought to be done, and the actions which correspond to this vision. Perhaps if Descartes had taken as his starting point the self as acting, this dichotomy would not have occurred. It is absent from the Bible, which speaks of obedience and disobedience, but not of theory and practice. When Jesus addresses the words 'Follow me' to a man, there is no gap between theory and practice: believing the one who calls and rising up to follow are two parts of one action. One can acknowledge the legitimacy of the protest by some theologians against a kind of theology which starts from theory and goes on to practice, but the dualism is not overcome by reversing the order and starting from practice. This only means that one acts on inadequately thought-out assumptions.

It is part of the consequence of the Cartesian method that we have become accustomed to the idea that 'science' represents a different kind of knowing from the rest of our knowing of the world. Science has been popularly understood to deliver a kind of indisputable and 'objective' array of 'facts' in contrast to the 'beliefs and values' which depend upon subjective factors. It is from within science itself that this misunderstanding is being corrected. Einstein has often been quoted as saying that "what you call "facts" depends on the theory that you bring to them'. So far as I know, the most comprehensive rebuttal of this view of science has come from the Hungarian scientist Michael Polanyi. ${ }^{3}$ The important thing to note about Polanyi's approach is that he was a working scientist with a significant record of fresh discoveries in the field of physical chemistry. His was not the approach of the philosopher who assesses the credentials of truth-claims, but the approach of the research scientist who is interested in the way by which we are led to make truth-claims. He draws on a vast experience of the world of science. to show that scientific discovery involves such factors as intuition, imagination, pertinacity, the willingness to take risks, and-above all-the capacity to make judgements where there are no formal rules to

3Polanyi, Personal Knowledge: Towards a Post-critical Philosophy (London, Routledge 1958). 
fall back on. The true scientist knows that he is on a journey towards a grasp of reality, not the possessor of indisputable and irreformable certainty, and that the justification of any truth-claim will be that it leads on to the discovery of further truth.

And there is surely a real continuity here with the kind of truth-claims which a Christian must make in his speech about God. Let me take, for example, the words of 2 Timothy 1:12: 'I know whom I have believed, and am sure that he is able to guard until that day what he has entrusted to me.' This is not a claim to the possession of an indisputable certainty of the kind that Descartes sought. The focus is not on the reliability of the knower's intellectual powers, but on the reliability of the One who is the object of knowledge. It is personal knowledge involving personal commitment in faith. It is significant that Polanyi's major work is entitled Personal Knowledge-a title intended to eliminate the objective/subjective dichotomy and to affirm that all human knowledge of any kind involves the personal commitment of the knower. And there is a further coherence between this biblical language and the way in which Polanyi tells us that the ground for a scientist's confidence in the truth of his findings is that they lead on to further truth. The apostolic writer looks forward to the day when we shall know in full. His present knowledge is not a complete, sealed-off certainty; it looks forward to fuller knowledge. Again the contrast with Descartes is clear. Here we are not claiming to be possessors of irreformable certainty; we are those who put their truth in One who is the truth and who will guide us into the fullness of the truth. Descartes saw mathematics as the paradigm of absolute certainty. But mathematics gives us formal statements which can only be applied to particular matters by an exercise of personal judgement which can never be completely formalised. It is relevant here to quote Einstein again. In different forms he often repeated the statement that 'Insofar as the statements of mathematics are certain, they make no contact with reality; insofar as they make contact with reality, they are not certain'. Polanyi paraphrases this by saying that only statements which can be doubted make contact with reality. That is, of course, a total contradiction of Descartes. But in the context of this discussion it is important to state the converse: statements which can be doubted do make contact 
with reality, or-at least-may make contact. Augustine saw faith as the path to knowledge. Descartes gave the prime role to doubt. Clearly both have necessary parts to play, but-as I have argued-faith is primary and doubt is secondary because rational doubt depends on faith. Plainly the affirmation which we make when we preach the gospel can be doubted. It is doubted by millions of people. They doubt it because they believe other things which can also be doubted. But the attempt of a certain kind of Christian to claim for the gospel the kind of indubitable certainty which was Descartes' claim must be seen to be mistaken. It is a surrender to a false rationalism. We walk by faith, not by sight.

There is another way of looking at the relation of faith to knowledge which is well illustrated in the history of science. At a crucial point in the long argument of Personal Knowledge, Polanyi uses a vivid metaphor. He says that the past 300 years of European history have been the most brilliant in all human history, that their brilliance was achieved by the combustion of a thousand years of tradition in the oxygen of Greek rationalism, and that the fuel is now exhausted so that pumping in more oxygen does not produce any more light. The point, of course, is that reason only works with something given, with data, with things which are accepted as a starting point. Reason is not a source of information about what is the case; it is the faculty by which we seek to discover the order and coherence in what is presented to us. All rational discourse takes place within a tradition which accepts some things as given. In the Christian tradition what is accepted as given is the story which the Bible tells with its centre in the events concerning Jesus. this is the given reality, the dogma. In much contemporary speech (I will not say 'thought') the word 'dogma' is treated as the opposite of all that it rational. But this arises from failure to examine one's own processes of thought. All rational discourse takes certain things for granted, certain things are given. In Christian language, this is the dogma. The difference is not between those who rely on dogma and those who do not; it is the difference between those who are explicit about the dogma on which they rely, and those who are unaware of it because they have simply accepted without criticism the reigning dogma of their culture. We are heirs of the Age of Reason which claimed that it could dispense with dogma and with 
tradition, using the tools of critical thought to dissolve what had hitherto been taken for granted. This has led us into nihilism. It is the claim of Polanyi, among others, that we have to face the responsibility of a post-critical age. We can never go back to a pre-critical age in which the authority of the Bible was regarded as beyond doubt. Once the critical questions have been asked, they cannot be silenced. What is now required is that we openly acknowledge that we accept as given, as dogma, that which can be doubted, that we have the courage to affirm as true what does not pass the Cartesian test of indubitable certainty.

This position is, of course, open to attack. In my experience I find that it is attacked from two sides: from the Catholic side it is accused of being a form of 'fideism', and from the evangelical side it is accused of subjectivism and relativism. I do not find myself intimidated by these charges, as I think they can be fully met.

In response to the charge of fideism, I think three things are to be said:

(1) The charge appears to rest on the illusion that there is available to us a kind of knowledge which does not rest on faith commitments. But the work of philosophers and historians of science has shown that this is an illusion. If I may quote one recent example, the book of Roy Clouser:4 The Myth of Religious Neutrality shows in considerable detail how major theories in mathematics, physics and psychology rest on presuppositions which are fundamentally theological in the sense that they posit the existence (not demonstrable a priori) of some reality on which everything else depends and which is not dependent on anything else. Without some such starting point, systematic thought cannot begin.

(2) We are not talking (as is often asserted) of a 'blind leap of faith'. We are speaking of a rational response to a personal calling. If the ultimate reality with which we have to do is, in some sense, personal, then the only way to knowledge will be through such a personal response to a personal calling. To exclude this possibility is to make a fundamental decision before the argument has started and is therefore irrational.

${ }^{4}$ Roy Clouser, Ethics (Notre Dame, University of Notre Dame Press 1991) 121. 
(3) The charge implies that the rational arguments of philosophy are more to be relied upon than the testimony of the apostolic witnesses to the events of the Gospel. This was certainly the view of Descartes. He held that the proof of the existence of God was a matter for philosophy, not for theology. It is of course absolutely right that the testimony of the apostles should be brought into the thinking of the philosophers and that rational thought should exercise itself in the task of relating that testimony to all the rest of human experience. But to suppose that this testimony cannot be trusted unless it is corroborated by philosophical argument which is (ex hypothesi) based on evidence other than this testimony, is already to have made a decision against that testimony.

(4) From a pastoral and apologetic point of view, I think it is worth pointing out that (as Michael Buckley has argued in At the Origins of Modern Atheism) it is precisely the 'God of the Philosophers' who is rejected by modern consciousness and is probably the main source of the specifically modern form of atheism.

The other charge, often coming from the conservative evangelical camp, arises from a justified protest against the subjectivism and relativism which is so characteristic of our culture. In this situation it is sometimes thought to be necessary to affirm the 'objective' truth of the Christian faith as something which is beyond doubt. This can sometimes lead to a kind of hard rationalistic fundamentalism which is remote from grace. It has been claimed that there are 'context-independent criteria' which are epistemologically more fundamental than the Christian affirmation that Jesus is Lord. Such criteria, it is claimed, include such things as the law of non-self-contradiction. But this 'law' is not context-independent. It is denied by very important elements in Indian philosophy which regard it as one of the defects of the western tradition. (It seems likely that the power of this principle in the western tradition arises precisely from the long schooling of Europe in the biblical tradition which affirms the ultimate coherence of the cosmos on the basis of faith in the faithfulness of God). But there is no 'context-independent' tribunal which could adjudicate between India and Europe. Only God has a viewpoint which is contextindependent. This kind of rationalistic fundamentalism has surrendered to the Cartesian illusion. It has accepted the idea, 
popularised in the 19th century propaganda for science as a substitute for religion, that there is a kind of 'objectivity' which eliminates the role of the subject in the business of knowing. It is remote from the biblical way of understanding reality with its centre and source in a gracious God who does not overwhelm us with indubitable certainties but woos us out of our estrangement with the appeal of his costly grace.

Here is the heart of the matter. A kind of 'indubitable certainty' which claims to possess knowledge is all part of our alienation from God. The reality is a gracious God who leads us into a knowledge of Him by a love which calls forth the commitment of faith. Faith is not a claim to indubitable and irreformable certainty. It is a personal and total personal commitment to the One who is able to lead us into truth in its fullness. I do not know of any better statement of the matter than the following words of Dietrich Bonhoeffer: ${ }^{5}$ 'Faith alone is certain. Everything but faith is subject to doubt. Jesus Christ alone is the certainty of faith'.

${ }^{5 D}$. Bonhoeffer, Ethics (ET, M. Horton Smith; London, SCM Press 1955). 